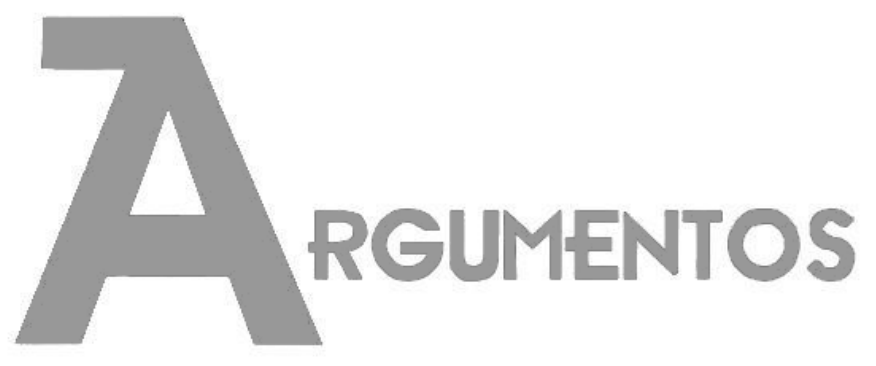

Vol. 18, n. 1, jan./jun. 2021 ISSN: 2527-2551 (online)

\title{
A formação de professores primários em Moçambique: qual modelo a adotar?
}

\author{
Wilson Profírio Nicaquela ${ }^{1}$ \\ Adelino Inácio Assane ${ }^{2}$
}

Recebido em: 22/09/2020

Aprovado em: $17 / 12 / 2020$

\begin{abstract}
Resumo: A partir da questão problemática: Que modelo adotar na formação de professores do ensino primário (básico) em Moçambique?, procuramos discutir várias alternativas que o país experienciou ao longo do tempo, desde a época colonial, passando pelo pós-colonialismo, até ao estágio atual. Analisar os diferentes modelos de formação de professores para o ensino básico em Moçambique foi o objetivo geral que definimos para desencadear acções, visando responder a questão problemática a qual levantamos neste estudo. Trata-se de uma pesquisa bibliográfica e recorremos ao método de revisão integrativa da literatura, para fundamentar os devires dos processos formativos de professores para o ensino básico em Moçambique. Ao mesmo tempo que incrementamos com as nossas reflexões baseadas em experiências profissionais, enquanto professores do Sistema Nacional de Educação em Moçambique uma situação que nos torna observadores observados (o auto-observadores ou observadores participantes). Este estudo foi realizado entre julho a setembro de 2020 no âmbito do doutoramento em Inovação Educativa na Faculdade de Educação e Comunicação da Universidade Católica de Moçambique. Em termos de conclusões, no final entendemos que o processo de formação de professores primários em Moçambique sempre sofre de mudanças cíclicas numa tentativa de responder a necessidade de oferta de professores de qualidade capazes de administrar um ensino de qualidade. Com efeito, a concepção de um modelo
\end{abstract}

\footnotetext{
${ }^{1}$ Doutorando em Inovação Educativa na Universidade Católica de Moçambique; Mestre em Educação em Ciências de Saúde pela Universidade Lúrio, Moçambique; Psicólogo escolar pela Universidade Pedagógica de Moçambique; Docente da Faculdade de Ciências Sociais e Humanas da UniLúrio, Fundador da Associação Moçambicana de Estudos Aplicados (AMEA) e do Grupo de Estudos e Pesquisas em Educação Popular e Cotidiano Escolar (GEPECE). E-mail: wilsonnicaquela@gmail.com. ORCID: https://orcid.org/0000-0001-6810-0655.

2 Doutor em Educação pela Universidade Federal Fluminense (UFF), Brasil; Mestre em EducaçãoFormação de Formadores e Licenciado em Pedagogia e Psicologia pela Universidade Pedagógica de Moçambique; Docente da Universidade Rovuma- e Nampula; Coordenador do Grupo de Estudos e Pesquisas em Educação Popular e Cotidiano Escolar (GEPECE). Director Científico da AMEA e Consultor Pedagógico da Paidéia \& Humanitas, Lda. E-mail:adiassane@yahoo.com.br. ORCID: https://orcid.org/0000-0001-7592-2817.
} 
consistente e capaz de satisfazer esse desejo, afigura-se ainda uma utopia. Capitalizar a formação contínua nas escolas sem finalidade de certificação pode constituir base para o desenvolvimento das práticas educativas dos professores já em exercício.

Palavras-chave: Educação, Ensino primario, Modelo de formação; Professores.

\section{La formación de profesores de primaria en Mozambique: ¿qué modelo adoptar?}

Resumen: De la pregunta problemática: ¿Qué modelo adoptar en la formación de maestros de escuela primaria (básica) en Mozambique? Buscamos discutir diversas alternativas que ha experimentado el país a lo largo del tiempo, desde la época colonial, pasando por el poscolonialismo, hasta la etapa actual. El análisis de los diferentes modelos de formación docente de educación básica en Mozambique fue el objetivo general que definimos para desencadenar acciones, con el objetivo de dar respuesta a la problemática pregunta que planteamos en este estudio. Se trata de una búsqueda bibliográfica y utilizamos el método de revisión integradora de la literatura, para fundamentar el futuro de los procesos de formación docente para la educación básica en Mozambique. Al mismo tiempo que aumentamos con nuestras reflexiones basadas en experiencias profesionales, como docentes del Sistema Nacional de Educación en Mozambique, situación que nos convierte en observadores (auto-observadores u observadores participantes). Este estudio se realizó entre julio y septiembre de 2020 en el ámbito del Doctorado en Innovación Educativa de la Facultad de Educación y Comunicación de la Universidade Católica de Moçambique. En cuanto a las conclusiones, al final entendemos que el proceso de formación de profesores de primaria en Mozambique siempre sufre cambios cíclicos en un intento de responder a la necesidad de ofrecer profesores de calidad capaces de administrar una educación de calidad. De hecho, el diseño de un modelo consistente capaz de satisfacer este deseo, todavía parece una utopía. Aprovechar la formación continua en las escuelas sin el propósito de la certificación puede constituir la base para el desarrollo de las prácticas educativas de los docentes que ya están en la práctica.

Palabras-clave: Educación, Educación primaria, Modelo de formación; Maestros.

\section{The training of primary teachers in Mozambique: which model to adopt?}

Abstract: From the problematic question: What model to adopt in the training of primary (basic) school teachers in Mozambique? We seek to discuss various alternatives that the country has experienced over time, from colonial times, through post-colonialism, to the current stage. Analyzing the different models of teacher training for basic education in Mozambique was the general objective we defined to trigger actions, aiming to answer the problematic question that we raised in this study. This is a bibliographic research and we use the method of integrative literature review, to substantiate the future of teacher training processes for basic education in Mozambique. At the same time we increase our reflections based on professional experiences, as teachers of the National Education System in Mozambique, a situation that makes us observers (self-observers or participating observers). This study was carried out between July and September 2020 within the scope of the PhD in Educational Innovation at the Faculty of Education and Communication of Catholic University of Mozambique. In terms of conclusions, in the end we understand that the process of training primary teachers in Mozambique always suffers from cyclical changes in an attempt to respond to the need of offering quality teachers able to provide quality education. Indeed, the design of a consistent model which can satisfy this desire, still seems to be an "utopia". Capitalizing on continuous training in schools without the purpose of certification can form the basis for the development of the educational practices for teachers already in practice.

Keywords: Education, Primary education, Training model; Teachers. 
Artigos | A formação de professores primários em Moçambique: qual modelo a adotar? (NICAQUELA, Wilson Profírio; ASSANE, Adelino Inácio)

\section{Introdução}

O processo de formação de professores para o ensino primário em Moçambique conheceu várias facetas. Enquanto alunos e professores do Sistema Nacional de Educação percebemos que, o atual estágio do subsistema de educação e formação de professores para o Ensino Primário (EP), teve muitos avanços e recuos. Durante a oscilação desses processos formativos, a educação foi ganhando, perdendo ou mantendo a(s) identidade(s).

Neste texto, procuramos descrever os modelos de formação de professores para o Ensino Básico, para tal, traçamos uma trajetória, partindo da educação no período colonial até a atualidade. Os modelos formativos de professores que vigoraram em cada época constituem o foco da discussão ao longo deste texto, num esforço sinuoso de apresentar uma possível variante de formação de professores ao longo da vida (formação contínua), usando como recurso a reflexão crítica suportada pela epistemologia da complexidade. Segundo MORIN (2013), o conhecimento complexo não é o que procura separar os fenómenos de forma especializada (questões da Psicologia, da Biologia, da Física, da Sociologia, da Antropologia, da Religião, da Educação, da Política e afins). A complexidade pauta pela articulação, mantendo a identidade e as diferenças dos fenómenos.

SANTOS (2006) alerta que vivemos uma simbiose que impede a prossecução do investimento de separação ou de hierarquização entre conhecimento científico/conhecimento tradicional, produção da sociologia/ produção da pedagogia, conhecimento do norte/conhecimento do sul. Ele não nega que haja especificações ou traços característicos, mas procura explicar que há uma completude entre as diferentes categorias sociais ou formas de produção do conhecimento.

Paulo Freire é um dos autores contestatários da opressão exercida sobre outras formas de produção de saberes, ou seja, um defensor pela mudança de paradigma. FREIRE (2000) contesta as teorias exclusivistas que desvalorizam pensamentos que, não sendo da matriz formalista, são secundarizados. O autor sugere outras modalidades de pensar e agir, mas sem necessariamente ignorar os outros. $O$ autor insiste no 
Artigos | A formação de professores primários em Moçambique: qual modelo a adotar? (NICAQUELA, Wilson Profírio; ASSANE, Adelino Inácio)

reconhecimento da diversidade e recorre a um discurso ético para justificar a tal diversidade:

Urge que assumamos o dever de lutar pelos princípios fundamentais como do respeito à vida dos seres humanos, à vida dos outros animais, à vida dos pássaros, à vida dos rios e florestas. [Ainda com recurso a metáforas, Freire prossegue:] Não creio na amorosidade entre mulheres e homens, entre os seres humanos, se não nos tornarmos capazes de amar o mundo (FREIRE, 2000, pág.67).

Encaixamos essa colocação na necessidade de reconhecimento mútuo e alternativo entre as diferentes formas e estratégias para a produção, processamento e partilha de conhecimento ou saberes, visto que se trata de um processo complexo. A ciência, de facto, é uma ecologia, onde a racionalidade precisa ser exercida liberalmente, o contrário gera o que Boaventura de Sousa Santos chama de perpetuação da razão metonímica. A razão metonímica é uma corrente do pensamento moderno ocidental que advoga a exaustão, exclusividade e completude de um modo de produzir conhecimento, ignorando que é apenas uma outra variante da racionalidade (SANTOS, 2006).

Experiências baseadas em narrativas são uma variante menos explorada nestas transições espontâneas que Moçambique vive desde a dominação colonial. Portanto, o saber da experiência pode ser alternativa para a formação contínua de professores do ensino primário (EP) em Moçambique, com base nas suas vivências, assumindo outra forma de desenvolver a densidade cultural, científica ${ }^{3}$ e pedagógica no exercício da atividade docente (NÓVOA, 2017).

\section{Pressupostos históricos da formação de professores em Moçambique}

Ao buscar a história da educação moçambicana, a penetração colonial apresenta-se como referência obrigatória, ou seja, a sua abordagem subdivide-se em épocas: antes da dominação colonial portuguesa, durante o regime colonial e o período pós-colonial. Embora de forma tímida, advogamos um possível 4o período na história de

\footnotetext{
${ }^{3}$ NÓVOA (2017) refere que o professor precisa de investir na cultura de leitura, na troca de experiências, na participação em eventos científicos, para além de se envolver densamente na pesquisa para que seja exemplo para seus alunos.
} 
Artigos | A formação de professores primários em Moçambique: qual modelo a adotar? (NICAQUELA, Wilson Profírio; ASSANE, Adelino Inácio)

educação em Moçambique, que compreende depois da guerra dos 16 anos até à atualidade. $\mathrm{O}$ argumento aqui apresentado é de que, as práticas educativas deste período foram influenciadas pela constituição de 1990, tornando algo totalmente diferente dos restantes períodos. (NICAQUELA, 2019; ASSANE, 2017).

Aliás, NGOENHA e CASTIANO (2019) no manifesto da 3ạ via advogam um outro modo de vida da sociedade moçambicana, eles buscam como referência a constituição de 1975, ano em que o país se tornou independente. Face às metamorfoses sociopolíticas, esses autores recomendam uma atualização das políticas públicas, inclusive as do setor da educação. Eles procuram construir argumentos que mostram as diferenças entre o antes e o depois da Constituição da República de 1990. No nosso entender, esse pensamento abre espaço para a atualização da periodicidade da história da educação em Moçambique.

Embora não seja o objetivo deste estudo discutir a história da educação, convém salientar que um dos motivos que contribuiu para a introdução do ensino formal em Moçambique foi o desejo de eliminar as práticas autótones, pois constituíam obstáculos na expansão do Império Português.

Portanto, a educação formal aparece associada àquilo que Boaventura de Sousa Santos chama de "razão indolente", que se manifesta (va) de diversas formas, isto é (i.e), aparece com discursos sobre o conhecimento hegemónico, tanto teológico, filosófico, assim como científico. Em outras palavras, a educação formal em Moçambique emerge no contexto do fortalecimento de estados liberais na europa ocidental, da revolução industrial, da edificação do capitalismo e da expansão colonial, que constituíram a base de desenvolvimento da "razão indolente" (SANTOS, 2006).

Assim, a introdução do ensino formal com a matriz exclusivamente europeia incluía escolas de formação de professores, com o intuito de dar cobro à educação capitalista, cujo fim era dinamizar a chamada civilização dos indígenas. Segundo HEDGES, MACHILI e SAÚTE (1995, pág.7):

O Governo colonial, na tentativa de estruturar um sistema de educação capaz de se aplicar na estrutura capitalista que emergia em Moçambique, organizou a partir de 1926 um sistema de ensino destinado aos indígenas. Assim, a criação da [Escola de Habilitação de Professores Indígenas] E.H.P.I., pela portaria no 312 de 1926, e a consequente abertura em 1930, era a concretização da finalidade da formação de um elemento da população 
moçambicana que agiria como intermediário entre o Estado Colonial e as massas, e inculcasse uma atitude de servilismo no moçambicano educado. De 1930 a 1940, a E.H.P.I. "José Cabral" organizada e dirigida pelo Estado teve programas caracterizados por um predomínio de disciplinas meramente de formação geral (programa de 1930 e de 1937), neutralidade religiosa, mudança de programas, conteúdos e tempo de duração e ausência de definição de conteúdos a leccionar o que pressupõe que seja resultado da luta decorrente no seio do Estado Colonial no que concerne à definição única sobre os objectivos e orientação do ensino indígena.

O processo de formação de professores em Moçambique é sistematicamente fundamentado e tem sofrido múltiplas transformações desde a vigência do colonialismo. Segundo NIQUICE (2005), essas transformações são contiguas aos objetivos e políticas das instituições que tutelam a educação na sua generalidade e o subsistema de formação de professores em particular, nomeadamente, o Ministério do Ultramar (durante o colonialismo) Ministério da Educação e Cultura, Ministério da Educação, período pós-colonial, e, agora, Ministério da Educação e Desenvolvimento Humano. ASSANE (2017) refere que, embora Moçambique tenha vivido 500 anos de dominação colonial e, nesses anos, se tenham desenvolvido processos educativos oficiais, apenas em 1930, foi criada a primeira instituição dedicada à formação de professores, a Escola de Habilitação de Professores indígenas do Alvor.

No período sob dominação colonial funcionaram igualmente escolas do Magistério Primário, que estavam vocacionadas à instrução de professores para o ensino primário (NACUO, 2008). Essa asserção corrobora com a constatação de Adriano Niquice em sua tese defendida em 2002 na Pontifícia Universidade Católica de São Paulo, sobre a formação de professores primários em Moçambique, que para além de apontar como segunda fase de implantação dessas instituições de formação para professores, por volta de 1962, indica igualmente que beneficiou apenas duas cidades Lourenço Marques (Maputo) e Beira. A fase final do colonialismo conheceu a abertura de Escolas de Habilitação de Professores do Posto Escolar constituídas em 1965 sob responsabilidade das Missões Católicas (NIQUICE, 2005).

A responsabilização das missões católicas na formação de professores surge no âmbito do acordo estabelecido entre a Santa Sé e o Governo Português designado concordata. Segundo HEDGES, et al (1995, pág.7) 
Artigos | A formação de professores primários em Moçambique: qual modelo a adotar? (NICAQUELA, Wilson Profírio; ASSANE, Adelino Inácio)

De 1941 a 1974, a escola organizada e dirigida pela Igreja Católica teve programas caracterizados por uma redução drástica do número de disciplinas dando-se maior primazia à repetição dos conteúdos da 4 a classe e o estudo do Português, Aritmética, Moral e Religião Cristã e a prática agrícola. Agora, o professor não só deveria ser habilitado como auxiliar defensor da língua e cultura portuguesas, como também de defensor da religião católica nas zonas mais recônditas da colónia. Apenas recebia alunos das escolas das missões católicas.

Entretanto, com a independência nacional, a educação moçambicana ficou severamente afetada. Os professores qualificados abandonaram o país. O MINEDH $(2017)^{4}$ refere que a contratação de sujeitos sem formação psicopedagógica para exercerem a profissão de professor foi uma das alternativas encontradas pelo Ministério de Educação e Cultura (MEC) [sic], para se fazer face ao défice de professores. Igualmente, "foram criados 10 Centros de Formação de Professores Primários (CFPP), para lecionarem da 1a à 4 a classe e 4 Centros Regionais". (MUGIME; MAPEZUANE; COSSA; \& LEITE, 2019, pág.5).

Para além do Centro 8 de Março, uma instituição de formação multidisciplinar de quadros moçambicanos no período pós-independência, que realizou a formação acelerada de professores do ensino secundário, aconteciam capacitações que variavam de 1 mês a 1 ano, até a introdução de Centros de Formação de Professores em diferentes regiões do país. Para o caso da Província de Nampula funcionaram os Centros de formação de Momola (Distrito de Nampula), Murrupula (Distrito de Murrupula), Marrere (Nampula -Cidade) e Nahadje (Distrito de Nacarôa). Entre 1980-1983 foram criadas novas escolas de formação de Professores (EFEP's) (GOLIAS, 1993; HEDGES et al, 1995 \& NIQUICE, 2005).

NACUO (2008, pág.191) refere ter emergido 4 EFEP's, sendo:

[...] Duas em Maputo Elidja Machava e a de Chibututuíne; uma na Beira e igual número em Nampula [...] As EFEP's vieram mudar o nome que o momento não gostava, porque cheirava, não se sabe em que medida, ao colonialismo, e aqui ficava patente a necessidade de não só formar o professor, mas educá-lo para as tarefas que o esperavam.

\footnotetext{
${ }^{4}$ Relatório do Estudo Holístico sobre o Estado de Professor em Moçambique realizado pelo Ministério da Educação e Desenvolvimento Humano
} 
Artigos | A formação de professores primários em Moçambique: qual modelo a adotar? (NICAQUELA, Wilson Profírio; ASSANE, Adelino Inácio)

A mentalidade com que se pretendia formar os professores e os propósitos que ditaram a mudança da denominação dessas instituições que culminou com a criação das EFEP's era para que fossem capazes de colocar em prática o projeto do homem novo, na complexa tarefa de "escangalhar" o aparelho ideológico colonial. Portanto, o Departamento de Educação (DEC) era a força motriz na definição das políticas de formação de professores, como se pode observar a seguir no discurso de Samora Machel, na 2ª Conferência do DEC:

[...] A este nível a missão dos professores e quadros da educação é extraordinariamente delicada. Porque eles, como nós, cresceram e formaram-se no mundo antigo, ainda trazem em si muitos vícios e defeitos, muito individualismo e ambição, muitos gostos corruptos e superstições, que são nefastos e podem contaminar as novas gerações. [....] Os professores e quadros da educação devem comportar-se como o médico, que antes de se aproximar do doente na sala de operações se desinfecta, se esteriliza, a fim de não infectar o paciente. (DEC, 1973).

A mudança de nome da instituição que se responsabilizava pela formação de professores durante a preparação do Sistema Nacional de Educação estava mais para afirmação política e ideológica do Estado independente de orientação socialista. GONÇALVES (2016) diz que o objetivo da educação depois de 1975 era a formação do homem novo, com convicções revolucionárias.

O subsistema de formação de professores em Moçambique, à semelhança dos projetos políticos do ministério de tutela, tem sido alvo de mudanças constantes de nomes das instituições formadoras e, por conseguinte, os modelos de formação ou cursos de professores (NIQUICE, 2005; NACUO, 2008).

O período de 1977-1991 foi considerado de consolidação das práticas de formação de professores no âmbito do SNE. Das mudanças ocorridas, houve a necessidade de alargar o tempo de formação, ou seja, transitou-se da contratação de sujeitos sem formação para a formação profissional num período mínimo de 2 anos, nos centros ora referidos, tanto para o EP, como para o Ensino Secundário (MUGIME et al, 2019).

Segundo o MINEDH (2017), para dar cobro ao elevado número de professores elementares e sem formação psicopedagógica, foi criado o Instituto de Aperfeiçoamento de Professores (IAP), esse instituto permitiu a formação em exercício, 
Artigos | A formação de professores primários em Moçambique: qual modelo a adotar? (NICAQUELA, Wilson Profírio; ASSANE, Adelino Inácio)

isto é, sem necessitar de os professores abandonarem as turmas para beneficiar de formação, consequentemente, a redução significativa de docentes de $\mathrm{N} 5^{5}$ para docentes de N4. Para além do IAP, foi criado o Instituto Nacional de Educação Física que formava professores de Educação Física para todos os níveis de ensino.

\section{Modelos de Formação de professores}

Como referi antes, a formação de professores para o ensino primário, em Moçambique, para lecionar da 1a à $7 \underline{a}$ classe, tem conhecido mudanças constantes, desde os nomes das instituições aos modelos de formação. Assim, NIQUICE (2005) apresenta cinco modelos que vigoraram desde a independência (1975) até a introdução dos Institutos de Magistério Primário (IMAP). Portanto, para além das capacitações e formações aceleradas, cuja duração variava entre 1-10 meses, ou 1 ano, o primeiro modelo de formação foi introduzido em 1982 (modelo de 6a classe+ 1 ano). Em 1983 apareceu o modelo de 6 $\underline{a}+3$ anos e em 1991 emergiu o modelo de $7 \underline{a}+3$ anos.

A trajetória revela que as mudanças de modelos continaram e no período que se seguiu ao Acordo Geral de Paz, houve recrutamento e capacitação de professores para o EP com duração de 2 semanas. Entretanto, em 1996 foram introduzidos os IMAP's cujo modelo de formação inicial era de $10^{\mathfrak{a}}+2$ anos (NIQUICE, 2005). Embora Niquice se limite em 5 modelos, outros autores como o caso de MUGIME et al (2019) defendem ter havido várias mudanças tanto nos modelos cuja base de ingresso era 7ạ classe, os que a base era $10^{\mathrm{a}}$ classe, assim como os que definem a $12^{\mathrm{a}}$ classe como pré-requisito de ingresso. Como se pode depreender, há muitos avanços e retrocessos no perfil de formação dos professores. Essas mudanças aconteceram por vezes de forma sequenciada, outras vezes, de forma difusa.

Recorrendo ao estudo de MUGIME et al (2019) esforçamo-nos em demonstrar as interpenetrações e (des)continuidades dos modelos formativos de professores dos diferentes subsistemas de ensino, e do ensino primário em particular, para encaixar o cenário atual, diferentemente da abordagem de NIQUICE (2005) que, não sendo ultrapassada, é passada na linguagem de MORIN (2008).

\footnotetext{
${ }^{5} \mathrm{O}$ qualificador das profissões em Moçambique categoriza com base no nível académico. Assim, os professores com nível elementar (7ạa classe) são considerados N5 e os com nível básico (10ạ) são N4.
} 
Artigos | A formação de professores primários em Moçambique: qual modelo a adotar? (NICAQUELA, Wilson Profírio; ASSANE, Adelino Inácio)

Assim, podemos identificar os seguintes modelos de formação de professores para o ensino primário a partir do nível de ingresso: cursos de base 7ạ classe (19911997), vigorou o modelo de 7ạ +3; posteriormente (1997-2003) foi introduzido o modelo de 7ạ+2+1. Enquanto nos cursos de base 10aㅡ classe, (1996-2007) foram introduzidos IMAPs com o modelo de 10 $\underline{a}+2$; em seguida (1999-2004) funcionou o modelo de 10ạ 1+1; atualmente (2007 até a presente data) funcionam os modelos de $10^{\underline{a}}+1$; modelo de 10a +3 ; e o modelo de $12^{\mathrm{a}}+3$ anos (MUGIME et al, 2019) que a seguir descrevemos de forma sucinta.

De forma deliberada, fazemos uma junção de certos modelos, sobretudo, os que o nível de ingresso é igual, variando na duração da formação

\section{Os modelos de 6a +1 e $6 \underline{a}+3$ anos}

Trata-se de um modelo de formação implementado consecutivamente em 1982 e 1983, cujo projeto político estava vinculado ao esforço de extinguir a mentalidade colonial e abrir bases para a implantação da ideologia socialista face à "1ạ República" que se achava nos primórdios da sua construção. 0 modelo de 6a +1 tinha duplo efeito, ou seja, primeiro objetivava o prolongamento da revolução que acabara de triunfar e pretendia a formação de homens com uma suposta nova mentalidade, distanciada de práticas nefastas e individualistas inauguradas pelo capitalismo. O esforço de prolongamento da revolução pela educação foi amplamente reproduzido pelo DEC, entidade que tutelava a educação dentro da Frente de Libertação de Moçambique (FRELIMO), conforme se pode ler a seguir:

Cada um de nós deve assumir com o ensino as suas responsabilidades revolucionárias. Conceber o livro, o estudo, como um instrumento ao serviço exclusivo das massas. Ver no estudo uma tarefa revolucionária, que deve ser combinada com as tarefas revolucionárias de produção e combate. Aquele que estudou deve ser o fósforo que vem acender a chama que é o Povo. A tarefa principal da educação, no ensino, nos livros de texto e programas, é inculcar em cada um de nós a ideologia avançada, científica, objectiva, colectiva, que nos permite progredir no processo revolucionário. A educação deve preparar-nos a assumir a nova sociedade e as suas exigências. (DEC, 1973/sp) 
Artigos | A formação de professores primários em Moçambique: qual modelo a adotar? (NICAQUELA, Wilson Profírio; ASSANE, Adelino Inácio)

Portanto, a introdução do curso de formação de professores para o ensino primário com o modelo 6a +1 ano acontece num período de total caos. Trata-se de um momento em que o país enfrentava déficit de quadros qualificados em todos os setores de atividades. GOLIAS (1993); NIQUICE (2005); GONÇALVES (2007) corroboram na ideia de que o subsistema de formação ou o SNE foi concebido como extensão dos programas de Educação em Zonas Libertadas, mas foi uma ação sinuosa, pois para além de enfrentar a resistência de como é típico na gestão de mudanças, não teve pessoas qualificadas capazes de implementar em todo o território nacional.

Portanto, a introdução da formação de professores do modelo 6 a +1 constituiu, em si, uma ação de duplo efeito, pois, por um lado, foi um marco significativo no rompimento oficial da formação baseada em princípios católicos que aconteciam nos centros de formação para professores do posto escolar, por outro lado, colocava em causa a qualidade de ensino. A depreciação das práticas educativas nos primeiros anos de implementação do SNE está diretamente ligada ao baixo nível conceptual dos professores responsáveis, embora muitos considerem como um problema recente, não é.

A nossa constatação não é primeira, aliás, o estudo holístico sobre o estado do professor em Moçambique, realizado pelo Ministério de Educação e Desenvolvimento Humano (MINEDH), refere que a questão de qualidade na formação dos professores tem constituído preocupação do setor, cuja efectivação irá contribuir substancialmente no aperfeiçoamento da qualidade de ensino que se almeja (MINEDH, 2017). Em relação ao modelo $6^{\mathfrak{a}+3}$ anos, este curso foi introduzido no mesmo ano da aprovação da Lei 4/83 que estabeleceu o 10 quadro jurídico-legal do setor de educação em Moçambique. Importa notar que trata-se de um sistema que, para além de cujos principais atores não deterem preparação adequada para a sua implementação, o número de candidatos para a formação era insuficiente em relação à demanda nacional. Portanto, a introdução do novo modelo, de 6a+3anos foi um exercício para contornar o défice formativo e conceptual dos professores com perfil elementar, que eram oriundos tanto dos antigos centros de formação de professores do posto escolar, assim como oriundos das EFEP, grupo que assegurou o funcionamento das instituições de ensino, sobretudo de nível primário entre 1976-1983. 
Artigos | A formação de professores primários em Moçambique: qual modelo a adotar? (NICAQUELA, Wilson Profírio; ASSANE, Adelino Inácio)

Tendo sido reconhecido o fraco nível de compreensão dos conteúdos curriculares, o novo modelo evidencia a componente pedagógica e disciplinas gerais. Assim, um dos objetivos do currículo de formação de professores do modelo 6a+3 anos era o domínio das bases teóricas que guiavam o Estado (o marxismo-leninismo) e o conhecimento do Mundo. (NIQUICE, 2005).

\section{Modelos de 7므 +3 anos e $7 \underline{a}+2+1$}

O itinerário da formação de professores primários e de outros subsistemas de ensino foi acompanhando as transformações socioeconómicas que se assentavam à medida que o tempo pervagava. Assim, a década de 90 foi o período em que mais se experienciou progressões e retrocessos em todo setor de educação e, na formação de professores, em particular.

Em 1991, um ano depois da aprovação da nova Constituição da República de Moçambique de 1990, que abriu espaço para o multipartidarismo, foi introduzido o modelo de formação de professores com $7 \underline{a}+3$ anos nos Centros de Formação de Professores, que substituíram as EFP's. Os graduados destes cursos assumiriam a missão de implementar o novo currículo de ensino instituído pela Lei 6/92, que atualiza o SNE.

Neste modelo, a primeira ruptura com o anterior foi a elevação da classe base de ingresso, ou seja, houve revogação e transição da 6a para 7ạ classe, ainda que mantivessem o período de formação de 3 anos para os professores primários do 1 o grau. À semelhança da preocupação manifestada no modelo antecedente, o modelo de $7 \underline{a}+3$ anos continua a evidenciar o esforço de melhoria das competências dos formados.

Para tornar-se mais saliente essa preocupação, foi incorporada no quadro jurídico-legal, que aprova o Sistema Nacional de Educação, como consta nos números 1, 2 e 3 do Artigo 33 da Lei 6/92 de 6 de Maio, que encerram o seguinte:

A formação de professores visa assegurar a formação integral dos docentes, capacitando-os para assumirem a responsabilidade de educar e formar os jovens e adultos. Conferir no professor uma solida formação científica, psicopedagógica e metodológica; permitir ao professor uma elevação constante do seu nível de formação científica, técnica e psicopedagógica. 
Artigos | A formação de professores primários em Moçambique: qual modelo a adotar? (NICAQUELA, Wilson Profírio; ASSANE, Adelino Inácio)

Portanto, o Estado moçambicano continua reconhecendo as lacunas existentes nos processos formativos e legaliza a necessidade da formação contínua dos professores dos diversos subsistemas de ensino, sobretudo, os professores do ensino primário que ingressavam em cursos iniciais com nível de escolaridade muito baixo. Entretanto, a manutenção do tempo de 3 anos para a formação de professores do EP1 não permitia um contato preliminar com a realidade prática dos futuros professores, ou seja, continuava a dar-se mais atenção a aspetos teóricos em detrimento de atividades profissionalizantes, tais como os estágios prolongados.

Como refere FRANCO (2011), não basta o saber científico, ou o saber da disciplina, para o sujeito em formação, por exemplo, transformar-se em bom professor. O cepticismo não se vincula automaticamente à questão do tempo de formação, pois quanto mais tempo for reservado, maior será a probabilidade dos formandos aprenderem e apreenderem as práticas profissionalizantes. A nossa constatação está na provável secundarização das atividades de estágio que deveriam ser parte da aprendizagem simbólica do saber fazer docente a partir das práticas profissionalizantes na interação com os professores mais experientes

O modelo de $7 \underline{a}+2+1$ constituiu uma engenharia curricular feita do modelo de 7a +3 anos entre (1997-2003). Este modelo, emergiu com duas finalidades: (1) para fazer face à necessidade de contato prolongado com a realidade prática de ensino através do estágio profissional por um ano e, (2) para dar cobertura a constante procura de professores, pois com a expansão da rede escolar o Ministério de Educação era obrigado a contratar sujeitos sem a componente psicopedagógica (Mugime et al. 2019).

\section{Modelos de $10^{\mathfrak{a}+2}$, 10aㅡ $+1+1$ e $10^{\underline{a}}+3$ anos de formação}

A formação de professores é diversa na duração, mas os IMAPs conservam um critério básico para o ingresso, desde a aprovação da Lei 4/83 (Lei do SNE), atualizada pela Lei 6/92 assim como na Lei 18/2018, ou seja, a exigência aos candidatos tem sido 10 a classe ou equivalente, portanto, a variação regista-se no tempo de formação como consta no título acima.

O modelo de formação de 10a +2 anos teve o seu início em 1996 na Cidade de Maputo, a essência era de formar professores para o Ensino Primário do 2o Grau- EP2. 
Artigos | A formação de professores primários em Moçambique: qual modelo a adotar? (NICAQUELA, Wilson Profírio; ASSANE, Adelino Inácio)

ASSANE (2017) refere que, nessas instituições, os cursos foram organizados em cinco especialidades de formação de professores: Uma especialidade que formava professores primários para as disciplinas gerais (Comunicação e Expressão e Matemática e Tecnologia); a segunda especialidade que formava professores para Educação Física; a terceira especialidade que formava professores para Educação Visual e Tecnológica; a quarta especialidade que formava professores para Educação Musical e a quinta especialidade formava professores para a língua inglesa. Todos os graduados destes cursos estavam habilitados para trabalharem nas escolas do Ensino Básico.

Convém referenciar que os CFPP continuavam simultaneamente a realizar os cursos de $7+3$ anos e $7+2+1$ que destinava os seus graduados para darem cobro ao ensino Primário do 1으 Grau - EP1.

Os graduados das três variações dos cursos oferecidos nos IMAP's para além da formação profissional beneficiam da formação académica. Ou seja, a vantagem era de obter um certificado equivalente ao nível médio. Essa abordagem integral coincide com o entendimento de MIALARET (1991) que considera a formação de professores como um processo ramificado, sendo uma a formação pedagógica ou profissional e a outra a formação académica. Para se ser professor, o saber da disciplina, que resulta das competências científicas adquiridas durante a formação académica precisam estar acoplados ao saber profissional.

LIBÂNEO (1994, p.22) considera a formação profissional como sendo "o conjunto de processos pedagógicos intencional e organizado, de preparação teórica, científica e técnica de professores para dirigir completamente o processo de ensino e aprendizagem". Nesse sentido, a formação profissional é a componente nuclear que permite ao professor conciliar os conhecimentos científicos adquiridos na formação académica-cientifica e a realidade prática imposta pelas várias situações do PEA. Insistimos na necessidade de procurar constituir-se um ponto de equilíbrio para que nenhuma das componentes seja relegada para planos secundários.

Diante das ideias de MIALARET (1991) e LIBÂNIO (1994) permite-nos concluir que nem a formação profissional a que era praticada exclusivamente nos modelos anteriores de $6+1$ por exemplo e muito menos o conhecimento académico, que os professores contratados com 10 $10^{a}$ classe, sem formação psicopedagógica, dispunham, servem isoladamente para um ensino que se preze de qualidade. Um professor bem formado é 
Artigos | A formação de professores primários em Moçambique: qual modelo a adotar? (NICAQUELA, Wilson Profírio; ASSANE, Adelino Inácio)

aquele que dispõe de uma formação integral. Esse modelo abre espaço para que, a posterior, o professor empenhe-se na sua aprendizagem contínua, numa perspetiva de autoformação.

Em relação ao Modelo de $10 \underline{a}+1$ ano, com o fim da guerra dos 16 anos em 1992, adesão de vários organismos internacionais, tais como o movimento de educação para todos declarado na conferência de Jom Tiem em 1990, a presença de movimentos de defesa de direitos da criança, no caso específico a Unicef, aderência aos objectivos de desenvolvimento do milénio (atuais objectivos de desenvolvimento sustentável ODS), esses fatores contribuíram para o alargamento da rede escolar no ensino primário e secundário.

O aumento da rede escolar teve como consequência imediata a elevação da demanda de professores. Assim, para fazer face à procura, o Ministério de Educação introduziu o curso de 1 ano, cujo fim último era de "formar mais professores em curto espaço de tempo e manter o crescimento da massa salarial, bem como a necessidade de responder aos desafios do milénio" (MUGIME et al 2019, pág. 5). Assim, à medida que o ensino primário ia crescendo, a procura pelo Ensino Secundário era irreversível, fazendo com que fosse necessário, também, a formação acelerada de professores para este nível de ensino. Primeiro aconteceu o modelo $12^{a}+3$ meses e, por fim, o modelo $12^{a}+1$ ano.

Há uma característica muito comum em todos os modelos ora elencados, os cursos têm um suporte curricular baseado em disciplinas e ou áreas de formação. A mesma constatação foi feita por NIQUICE (2005); ASSANE (2017). Segundo ZABALZA (2001, p.112), no modelo curricular baseado em disciplinas e aprendizagens formais “[...] dá-se muita importância aos conhecimentos a adquirir. Organizam-se os espaços, tempos e actividades em função de tais conhecimentos. Procuram-se resultados, diretamente comprováveis como produto da instrução".

\section{Estratégia de formação de professores em Moçambique}

Desde 1975, em Moçambique, a educação deixou de ser luxo e passou a ser um direito e dever, de todos os moçambicanos. Esforços são tantos que o Governo experimenta a efectivação da política de educação para todos e ameniza os principais 
Artigos | A formação de professores primários em Moçambique: qual modelo a adotar? (NICAQUELA, Wilson Profírio; ASSANE, Adelino Inácio)

problemas relacionados com o acesso, qualidade de ensino e custos e sustentabilidade do sistema educacional (MINED, 1998).

Como nos referimos na parte final da abordagem sobre os modelos de formação de professores, a política expansionista de educação arrasta consigo outros problemas que precisam de soluções, muitas vezes, quase de forma espontânea. Portanto, o descerramento de novas escolas carece professores. Assim, nos diferentes Planos Estratégicos de Educação - (1999-2003; 2006-2011; 2012-2016 e 2019-2023) tem sido colocada em destaque a formação inicial e em exercício de professores para o Ensino Primário.

Embora haja abordagem da formação inicial em todos os PEE, com foco no domínio de conteúdos curriculares e a aquisição de competências técnico-científicas e psicopedagógicas, para que o professor possa sobreviver na sala de aulas (MINED 1998; MEC, 2006 e 2011; MINEDH, 2019), nota-se nos 4 planos estratégicos a manutenção e referência da formação em exercício, como indicador de qualidade de ensino associado a progressões na carreira. Portanto, o foco da formação em exercício se concentra na execução da profissão (lecionação), estabelecimento e efectivação das relações com os pais e/ou encarregados de educação, assim como outros membros da comunidade.

As formações (inicial e em exercício) foram concebidas como estratégia de profissionalização da função docente, para além de incrementar os esforços, para a redução da falta desses profissionais, através da formação quantitativa de professores. Curiosamente, há uma contradição conceptual sobre a formação em exercício e contínua de professores do ensino primário, pois, enquanto de um lado os PEEs referem da sua efectivação, que acontece ao nível local (na escola), por outro, faz menção da criação duma direç̧ão nacional para a formação, que tem o mandato de operacionalizar e supervisionar todas as formações de professores. Este órgão do MINEDH emergiu depois do Instituto de Aperfeiçoamento de Professores que tutelava a formação inicial, esta contradição resvala naquilo que ASSANE (2017) chama por formatação.

Nesse sentido, entendemos que há uma fusão menos coerente nos PEE, de três formações diferentes, nomeadamente: continua, em exercício e recorrente. Essa fusão, faz com que a formação contínua se mostre mais formal e institucional, embora se preze diferente da inicial. Nos moldes em que é tratada objetiva a elevação do nível académico 
Artigos | A formação de professores primários em Moçambique: qual modelo a adotar? (NICAQUELA, Wilson Profírio; ASSANE, Adelino Inácio)

dos beneficiários através da certificação, como se pode constatar no PEE 1999-2003 onde consta que os professores recém-contratados sem formação:

Recebem uma breve orientação profissional, antes de entrarem nas salas de aulas e subsequente formação em exercício, tanto em programas residenciais como através de formação à distância. O MINED providenciará supervisão, apoio pedagógico e formação contínua em exercício, com prioridade para os novos professores. Com o andar do tempo, o MINED procurará assegurar que todos os professores do ensino primário tenham, pelo menos, 10 anos de escolaridade e uma formação profissional completa, mas está claro que esta meta só será alcançada a longo prazo. (MINED, 1998, pág.20)

Essa miscelânea pode ser um dos factores que cria limitações na realização de encontros entre professores na escola para a sua autoformação a partir da partilha de experiências sem esperar que alguém venha orientar a formação e atribuir certificados. A formação contínua deveria constituir um método de aperfeiçoamento integral e efectivação da autonomia pedagógica. Segundo MABOTE (2004, p.58), a formação em exercício é o "conjunto de processos de formação permanente do professor e da comunidade escolar, articulando, assim, a formação inicial e a formação contínua". Essa formação contempla acções programáticas desenvolvidas para um acompanhamento de professores a partir do exercício das actividades docentes, a qual permite uma capacitação sistemática para o sucesso do PEA. Um individuo que esteja na formação inicial pode complementar a sua formação durante o trabalho prático, aí estaremos diante da formação em exercício.

A formação contínua de professores não significa, necessariamente, a atribuição de títulos académicos. Também, não é um ato de imposição, a formação contínua devia ser de carácter voluntário e pessoal, através das necessidades que os professores têm a partir da sua prática cotidiana. Em momento algum, os PEE falam do envolvimento de professores mais experientes para contribuir na construção do saber profissional dos professores recém-formados, nos diferentes modelos, nomeadamente, os de base 7ạ classe, os de base 10 $10^{a}$ classe, nem a de base 12a. Através de NÓVOA $(2009$, p.36), entendemos que "a formação de professores deve passar para "dentro" da profissão, isto é, deve basear-se na aquisição de uma cultura profissional, concedendo aos professores mais experientes um papel central na formação dos mais jovens". 
Artigos | A formação de professores primários em Moçambique: qual modelo a adotar? (NICAQUELA, Wilson Profírio; ASSANE, Adelino Inácio)

Ao abordar a estratégia para a formação de professores em Moçambique, o MINED não revela em que contextos e nem refere o grupo de professores experientes como potenciais actores com quem se pode contar nessa empreitada que, provavelmente, tem seu início durante a formação inicial e nunca mais conhece o seu fim, enquanto o exercício da função docente estiver no activo. ESTEVES (2014, Pág. 119120) propõe que a formação contínua:

[...] Deve constituir-se a partir de uma rede de comunicação, que não se deve reduzir ao âmbito dos conteúdos académicos, incluindo também os problemas metodológicos, pessoais e sociais que, comumente, se entrelaçam com as situações de ensino. A inovação educativa está sempre ligada à existência de equipas de trabalho que abordam os problemas em comum, refletindo sobre os sucessos e as dificuldades [...] O contacto com os colegas é fundamental para a transformação da atitude e do comportamento profissional, nomeadamente com os grupos portadores de uma perspetiva inovadora, cuja experiência permite visualizar ações e realidades concretas.

Olhando para as posições assumidas tanto por NOVOA (2009) assim como por ESTEVES (2014), e conjugadas com o real cenário da formação de professores em Moçambique, existe uma tendência de se repetir os mesmos processos em cada alternativa que se pretendem adotar para tornar o professor mais habilitado e profissional. Entretanto, a partilha de experiências que é menos valiosa na nossa realidade parece ser um aspeto extremamente relevante a tomar-se em consideração e, sobretudo, na implementação da formação contínua a partir da escola e com a escola.

\section{Notas conclusivas}

Quando analisamos os diferentes modelos e a política de formação de professores primários em Moçambique, desde o período colonial em Moçambique, até 1975, ano da Independência Nacional, constatamos haver uma ruptura e (des) continuidades por vezes (des) necessárias. Ou seja, há interrupções e retomas dos mesmos modelos de formação sem se fazer mudanças significativas no plano curricular e/ou conteúdos de formação. Todas as variantes formativas adotadas nos diferentes momentos e modelos de formação, o Ministério de Educação, que assume a tutela deste 
Artigos | A formação de professores primários em Moçambique: qual modelo a adotar? (NICAQUELA, Wilson Profírio; ASSANE, Adelino Inácio)

subsistema de formação (Ministerio de Educacao, outras vezes chamado Ministerio de Educacao e Cultura, ou Ministerio de Educacao e Desenvolvimento humano), privilegia uma formação baseada em disciplinas. Acreditamos na base das reflexões que vimos desenvolvendo ser o interesse pela formação académica, que inviabiliza a clareza na definição de estratégias de formação contínua de professores. Isto é, nos diferentes planos estratégicos de educação nota-se uma ambiguidade no que se refere à estratégia de formação contínua de professores, fazendo com que o processo seja uma reedição das formações iniciais, as quais funcionam na modalidade presencial ou à distância. A falta de envolvimento de professores e outros atores nos estudos preliminares, para a revisão das políticas de formação de professores, constitui um dos maiores embaraços para a efetivação e adoção de um modelo que se mostre eficaz e eficiente para a formação de professores do ensino primário. Uma formação baseada na partilha de experiências entre os mais experientes e os que acabam de ingressar na carreira docente se afigura alternativa válida e viável na actualidade.

\section{Referências}

ASSANE, A. I. Práticas Curriculares no Ensino Básico: Tecendo e Narrando Redes de Experiências na Formação Continuada de Professores da Disciplina de Ofícios em Moçambique (tese de Doutoramento em Educação). Universidade Federal Fluminense. Niterói. 2017.

DEC - Departamento de Educação e Cultura. EDUCAR O HOMEM PARA VENCER A GUERRA CRIAR UMA SOCIEDADE NOVA E DESENVOLVER A PÁTRIA (Mensagem do Camarada Samora Machel, Presidente da Frelimo, à 2a Conferência do Departamento de Educação e Cultura-) Coleção «Estudos e Orientações» № 2, 1973.

ESTEVES, J. M. Mudanças sociais e função docente. In: Nóvoa, A. (Org) (2014). Profissão Professor. 2ed. pp. 93-124. Porto: Porto Editor., 1999.

FRANCO, M.A.S. Prática docente universitária e a construção colectiva de conhecimentos: possibilidades de transformações no processo de ensino-aprendizagem. In: Pimenta, S.G. \& Almeida, M.I. (Orgs). Pedagogia Universitária: caminhos para a formação de professores. Cortez. São Paulo. (pp.159-187) 2011.

FREIRE, P. Pedagogia da indignação: cartas pedagógicas e outros escritos. São Paulo: Editora UNESP, 2000.

GOLIAS, M. Sistemas de Ensino em Moçambique: Passado e Presente. Maputo: Editora Escolar, 1993.

GONÇALVES, A. C. P. A Politécnica Como Princípio Pedagógico Em Moçambique: contradições de um discurso socialista In: Educação e Pesquisa, São Paulo, v.33, n.3, p. 601-619, set./dez. 2016. Disponível em: . 
Artigos | A formação de professores primários em Moçambique: qual modelo a adotar? (NICAQUELA, Wilson Profírio; ASSANE, Adelino Inácio)

HEDGES, D.; MACHILI, C. \& SAÚTE, A. R. Escola de habilitação de professores indígenas José Cabral, Manhiça - Alvor: subsídios para o estudo da formação da elite instruída em Moçambique (1926 - 1974). Repositório de Monografias UEM. Maputo, Mocambique: Imprensa Universitária, 1995. Dísponivel em: http://hdl.handle.net/123456789/1121. acesso em 12/07/2020.

LIBÂNEO, J. C. Didática. São Paulo: Cortez editora, 1994.

MABOTE, J. A. Manual de Supervisão Pedagógica. Maputo: Editora DNEB/INDE, 2004.

MEC- Plano Estratégico de Educação. 2006-2011/12. Maputo, 2006.

MIALARET, G. A Formação dos Professores. Coimbra: Livraria Almedina, 1991.

MINED - Plano Estratégico de Educação. 1999-2003. Maputo, 1998.

MINED - Plano Estratégico de Educação. 2012-2016. Maputo, 2012.

MINEDH - Plano Estratégico de Educação. 2020-2024. Maputo, 2019.

MINEDH - Relatório do Estudo Holístico da Situação do Professor em Moçambique. Edição: MINEDH. Maputo, 2017.

MOÇAMBIQUE. Assembleia da República. Lei 6/92 de 6 de Maio. Lei do Sistema Nacional de Educação, Maputo, 1992.

MORIN, E. Ciência com consciência. Edição revista e modificada pelo Autor. 15Ed. Tradução de Alexandre, M.D. e Dória, M.A.A. de S. Bertrand Brasil. Rio de Janeiro, 2013.

MORIN, E. Introdução ao pensamento complexo. Tradução de Matos, Dulce. Colecção Epistemologia e Sociedade. Instituto Piaget. Lisboa, 2008.

MUGIME, S. M. J., MAPEZUANE M., F., COSSA, J., \& LEITE, C. Estudos sobre formação inicial de professores em Moçambique e sua relação com as políticas de formação de professores (2012-2017). Arquivos Analíticos de Políticas Educativas, 27 (149), 2019. https://doi.org/10.14507/epaa.27.4250

NACUO, P. Boroma: Homenagem a todos os Professores. 2ed. Maputo: Publicações Notícias, 2008.

NICAQUELA, W. P. Conhecimentos dos Adolescentes sobre a Saúde Sexual e Reprodutiva. 2019 Disponível em <https://www.morebooks.de/store/pt/book/conhecimentosdos-adolescentes-sobre-educa\%C3\%A7\%C3\%A3o-sexual-reprodutiva/isbn/978-613-9-794157>NGOENHA, S.E., CASTIANO, J.P. Manifesto da terceira via - Ponto um, 2019. Disponível em https://anchor.fm/severino-ngoenha/episodes/Manifesto-da-terceira-via-ponto-1-e3s1c0

NIQUICE, A. F. Formação de Professores Primários: Construção do Currículo. Maputo: Texto Editor, 2005.

NÓVOA, A. Desafios do Trabalho e formação docente no Seculo XXI. In Palestra com os professores do Sindicato dos Professores de Nova Hamburgo, 2017.

NÓVOA, A. O passado e o presente dos professores. In Nóvoa, A. (Org) . Profissão Professor. 2ed. Porto: Porto Editor. p. 13-34, 2014.

NÓVOA, A. Professores: Imagens do futuro presente. EDUCA Instituto de Educação Universidade de Lisboa, Lisboa, 2009.

SANTOS, B. S. Para uma Sociologia das ausências e uma Sociologia das emergências. In Santos, B.S (2006) (Org). Conhecimento Prudente para uma vida decente: um discurso sobre as ciências. Revisitado. 2ed. São Paulo: Cortez editora, 2006.

ZABALZA, M. A. Planificação e Desenvolvimento Curricular na Escola. Rio Tinto: ASA Editores, 2001. 